\title{
Episodic ataxia with slurred speech
}

INSERM

\section{Source}

INSERM. (1999). Orphanet: an online rare disease and orphan drug data base. Episodic ataxia with slurred speech. ORPHA:401953

Episodic ataxia with slurred speech is a rare hereditary ataxia characterized by recurrent episodes of ataxia with variable frequency and duration, associated with slurred speech, generalized muscle weakness and balance disturbance. Other symptoms may occur between episodes, including intention tremor, gait ataxia, mild dysarthria, myokymia, migraine and nystagmus. 